\title{
BASE DE DADOS DA CIDADE DE FEIRA DE SANTANA-BA: CONTRIBUIÇÃO DO PET GEOGRAFIA-AGRONOMIA PARA MELHOR CONHECER INFORMAÇÕES SOBRE NOSSO MUNICÍPIO
}

\author{
Brenda de Souza Santino'; Joselisa Maria Chaves'; Victor Lopes Matos Silva ${ }^{3}$ \\ 1. Bolsista PIBIC/CNPq, Graduando em Agronomia, Universidade Estadual de Feira de Santana, e-mail: \\ brendda.28.bs@gmail.com \\ 2. Orientadora, Departamento de Exatas, Universidade Estadual de Feira de Santana, e-mail: \\ josimariachaves@gmail.com \\ 3. Participante do projeto PET Geografia-Agronomia, Estudante do curso de Física, Departamento de Fisica, \\ Universidade Estadual de Feira de Santana, e-mail: \\ victor.lopesm@hotmail.com
}

PALAVRAS-CHAVE: Geotecnologias; Semiárido; GeobaseUefs

\section{INTRODUÇÃO}

Atualmente vivemos na era da informação, onde a todo instante dados são disponibilizados de inúmeras formas, sejam nas escolas, bibliotecas, instituições de ensino Superior, ou mesmo na internet. Essa imensa quantidade de informações geradas criam a necessidade do desenvolvimento de sistemas onde esses materiais possam ser organizados e disponibilizados de forma simples e de fácil acesso para quem os procura. Com esse intuito são criados os Bancos de Dados, que são conjuntos de informações que relacionam entre si, proporcionam a troca, recebem, armazenam, processam e apresentam a informação, onde esta é utilizada na forma pretendida pelo usuário (Graziosi et al 2011).

Quando os primeiros bancos de dados foram desenvolvidos, a principal preocupação era criar um sistema capaz de permitir a modelagem de qualquer tipo de informação (Samary 2007). Só na década de oitenta que houve o surgimento dos grandes bancos de dados relacionais, juntamente com normas e restrições que serviam para nortear os analistas no processo de desenvolvimento. Ainda nessa mesma década, a literatura especializada registrou um forte movimento no sentido de prover ao usuário final os instrumentos necessários para que o mesmo realizasse suas próprias busca (Lopes 2002). Esse processo permitiu o desenvolvimento de inúmeras interfaces como o Google Acadêmico e o próprio site do Instituto Brasileiro e Estatística (IBGE), que ao longo do tempo estão sendo aprimoradas para facilitar o acesso e acelerar as buscas.

A cidade de Feira de Santana, que é a segunda maior cidade da Bahia, engloba hoje uma enorme produção científica advinda das instituições de Ensino Superior públicas e privadas, além de um Instituto Federal. Porém, o acesso à dados e produções relacionados a cidade é dificultado, principalmente pela falta de uma fonte segura que concentre todas essas informações. Pensando na necessidade de junção dessas produções de forma segura e de fácil acesso, além daquelas que ainda virão a existir criou-se o GEOBASEUEFS. O objetivo desse trabalho é apresentar essa base de dados de Feira de Santana, que além de servir como fonte para consulta em pesquisas realizadas pela comunidade acadêmica, também poderá contribuir para elaborar material didático que auxilie os professores no processo de ensino-aprendizagem nos ensinos fundamental, médio e superior.

\section{METODOLOGIA}

A metodologia desse trabalho foi realizada em três etapas. Na primeira etapa foi feita uma revisão bibliográfica onde foram pesquisadas as fontes para a realização da pesquisa e elaboração da Base de Dados. Nessa mesma etapa ocorreu a aquisição de dados provenientes de Bibliotecas, Bancos de Dados de entidades como o IBGE, SIGBAHIA, 
revistas científicas, Google Acadêmico, Anais de eventos e do banco de dados do Programa de Pós-graduação em Modelagem em Ciências da Terra e do Ambiente (PPGM). Já na segunda etapa foi feita a estruturação e desenvolvimento do sítio. A linguagem de programação escolhida foi o Hypertext Preprocessor (PHP) juntamente com o Structured Query Language (SQL) que hoje são amplamente utilizadas no desenvolvimento de banco de dados Web.

A terceira etapa constituiu-se no processo de apuração dos dados, que foram divididos nas categorias Artigos, Teses e Dissertações, Imagens Satélite, Dados Demográficos e Arquivos Vetoriais Espacializados, para melhor entendimento e análise. Para facilitar a utilização do usuário, algumas alterações precisaram ser feitas nos arquivos vetoriais para que fossem disponibilizados como informações relacionadas apenas ao município. Para a validação, procurou-se identificar e eliminar as construções redundantes (Heuser,2004). Após a seleção, os dados foram inseridos no GEOBASEUEFS. A metodologia pode ser melhor observada na figura 1.

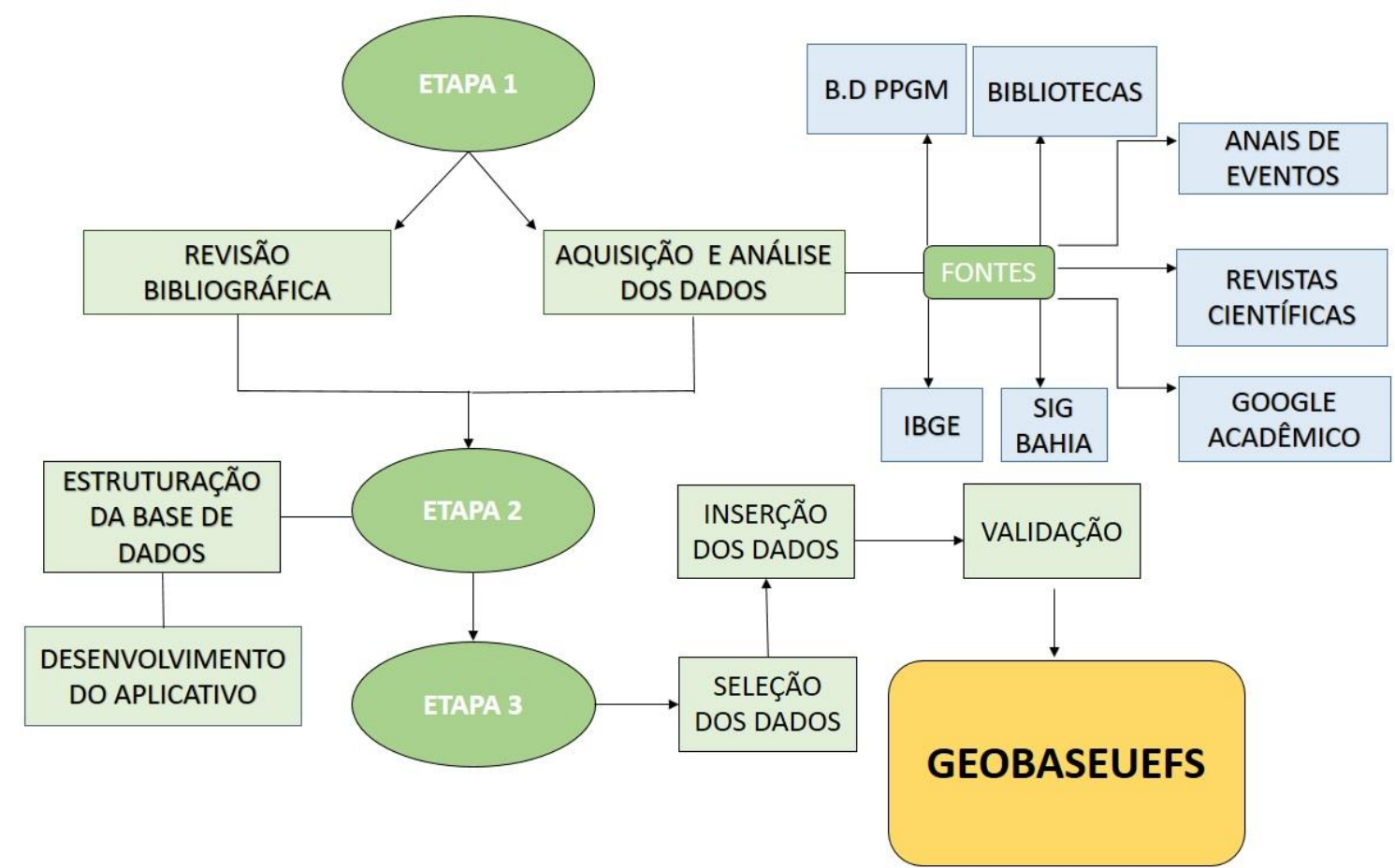

Figura 1: Fluxograma representando a metodologia utilizada no processo de desenvolvimento da base de dados GEOBASEUEFS.

\section{RESULTADOS E DISCUSSÃO}

Na construção da base de dados proposta, denominada GEOBASEUEFS, foi levada em consideração a confiabilidade das informações contidas, desde a primeira fase de levantamentos de dados. Ademais, foi feito levantamento de dados e informações em diferentes fontes que envolvessem o objeto de estudo, Feira de Santana, e dos demais assuntos relacionados à cidade, além de serem elaborados quadros para organização dos dados e eliminação das informações redundantes. Como pode ser observado na tabela 1 , os dados adquiridos foram separados em categorias e foram definidas as fontes de cada um deles. Pode ser observado também que as quantidades de dados inseridos no banco foram menores em relação aos adquiridos, algo natural do processo de seleção, já que o usuário final precisará encontrar não somente uma grande quantidade de informações, mas que também sejam confiáveis e não repetitivas.

Para disponibilização de uma plataforma acessível, foi pensado um banco de dados online, onde qualquer pessoa que tenha internet a sua disposição possa buscar 
informações e fazer downloads dos arquivos. As consultas são enviadas no formato SQL para o servidor, que as processa e retorna apenas os dados solicitados (Lobão et al., 2005). Foi usado também o Bootstrap que é responsável por facilitar o uso da base por dispositivos móveis. O usuário pode fazer as buscas através de palavras-chave que foram definidas no momento da entrada do dado específico. Além disso, é possível fazer também um refinamento por categorias, pré-definidas nas abas de busca pelo próprio site, ou simplesmente na aba "explorar" pode ser solicitado a visualização de todos os arquivos (Figura 2).

Tabela 1. Categorias com respectivas quantidade e fontes dos dados usados na pesquisa.

\begin{tabular}{c|c|c|c} 
Tipo de dado & Quantidade & Fontes & $\begin{array}{c}\text { Quantidade de dados } \\
\text { inseridos no banco }\end{array}$ \\
\hline Artigos & 200 & $\begin{array}{c}\text { Google Acadêmico, Anais de } \\
\text { Eventos, } \\
\text { Lattes de pesquisadores da UEFS. }\end{array}$ & 22 \\
\hline Teses e dissertações & 384 & $\begin{array}{c}\text { Google Acadêmico, acervo da } \\
\text { Biblioteca Digital da UEFS }\end{array}$ & 24 \\
\hline Imagens Satélite & 24 & Banco de Dados do PPGM & 123 \\
\hline Dados demográficos & 147 & $\begin{array}{c}\text { Banco de Dados IBGE, DETRAN, } \\
\text { INEP }\end{array}$ & 28
\end{tabular}

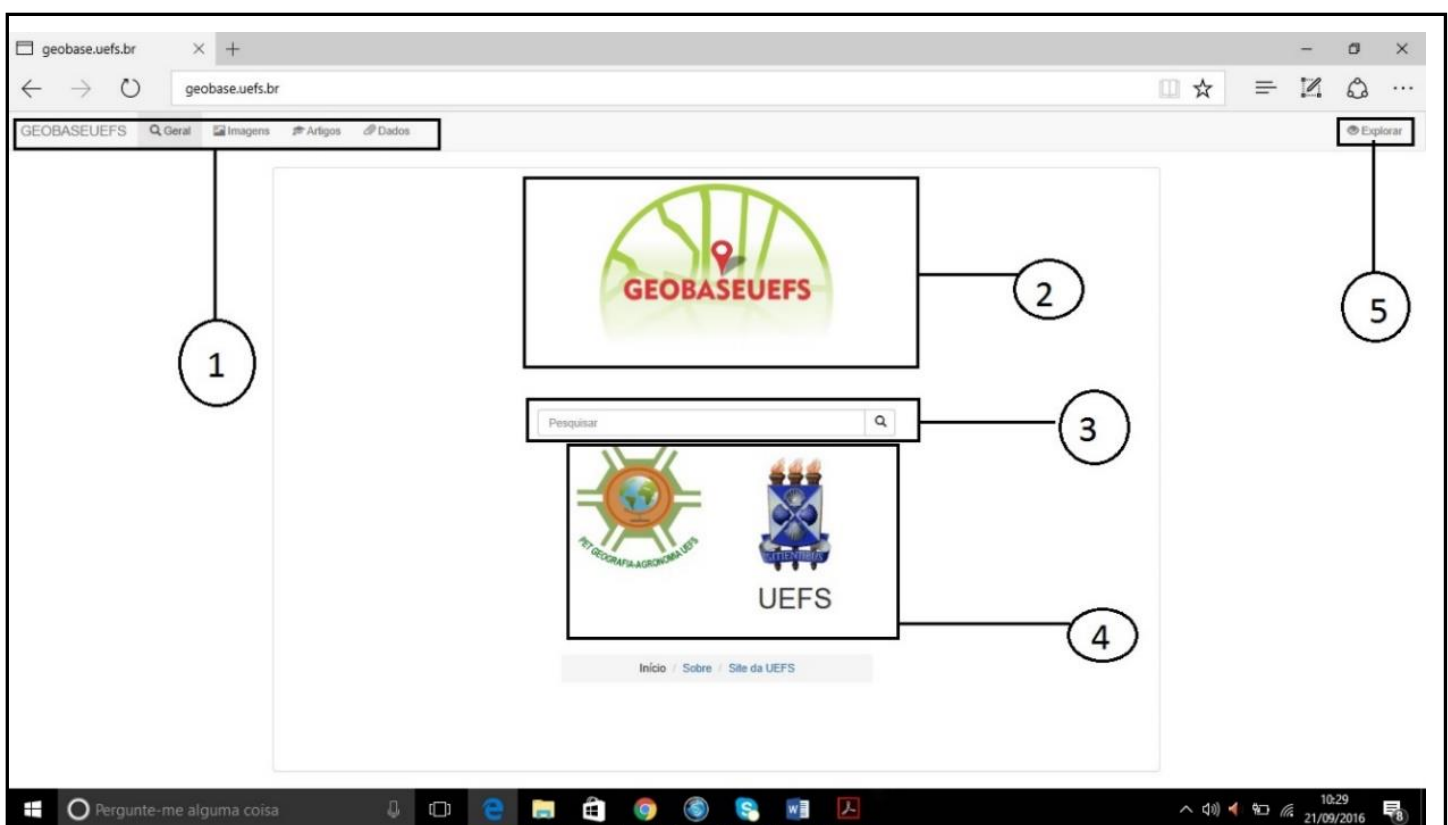

Figura 2. Interface gráfica da Base de Dados: 1-Aba de busca 2-Logotipo da base de dados 3-aba de pesquisa 4-Logotipo e Brasão dos patrocinadores 5- Janela de exploração dos dados.

Fonte: www.geobase.uefs.br

Para a manutenção do fluxo de dados e para evitar que as informações deixem de ser confiáveis, existem os administradores, que são constituídos pelos pesquisadores (professores e discentes da UEFS) do grupo PET Geografia- Agronomia que irão 
principalmente monitorar, avaliar, cuidar da manutenção e fluxo da as informações. Como também, contar-se-á com os responsáveis pelas informações do site do PPGM (Programa de Pós-graduação Modelagem em Ciências da Terra e do Ambiente) que atuará no processo inserção de dados espaciais, imagens, shapes, artigos e etc. Na figura 2 é possível ver um gráfico que demonstra a atual configuração da quantidade de dados presentes no banco nesse momento. É importante salientar que essas proporções são alteradas de acordo com a quantidade e tipologia dos dados que são inseridos ao longo do tempo.

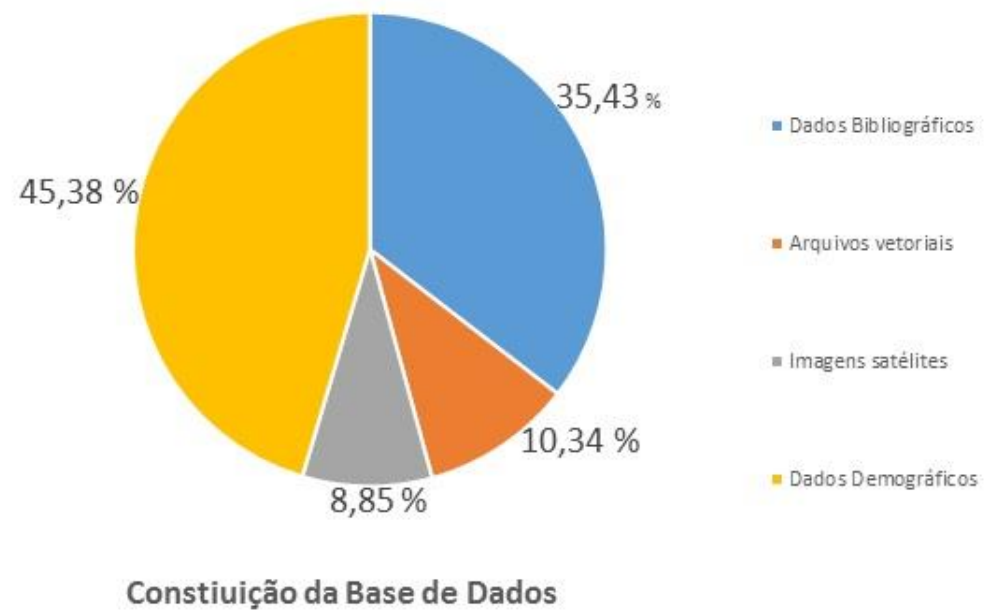

Figura 3. Gráfico de demonstra a atual constituição da base de Dados, de acordo com as categorias selecionadas.

\section{CONSIDERAÇÕES FINAIS}

O banco de dados " GEOBASE UEFS" é primeira plataforma online e gratuita de pesquisa de informações e dados sobre a cidade de Feira de Santana, através de uma interface simples e eficaz, apresenta um material acessível e que proporciona a comunidade escolar e acadêmica à troca de informações e conhecimento.

\section{AGRDECIMENTOS}

Os autores agradecem a UEFS e o PPGM pelo suporte, também a FAPESB e CNPq pelo apoio financeiro.

\section{REFERÊNCIAS}

LOPES, I.L.; 2002. Uso das linguagens controlada e natural em bases de dados: revisão da literatura. Ci. Inf., Brasília, v. 31, n. 1, p. 41-52, jan./abr.

HEUSER, C. A. 2004. Projeto de Banco de Dados. Série Livros Didáticos n 4. Rio Grande do Sul: Sagra Luzzatto, $5^{\mathrm{a}}$ ed.

LOBÃO, J. S. B; LOBÃO, J. A. L; ROCHA, W. J. S. F. 2005. Banco de Dados Biorregional para o Semi-Árido no Estado da Bahia. IN: Anais XII Simpósio Brasileiro de Sensoriamento Remoto, Goiânia, Brasil, 16-21 abril 2005, INPE, p. 2237-2244.

SAMARY, A.2007. História dos Bancos de Dados e tendências futuras. SQL Magazzine, $21^{\mathrm{a}}$ ed.

NEVES, R. C.; TEIXEIRA, N.T.2009. A construção de um banco de dados geográfico e suas aplicações para o ensino da geografia. Anais $10^{\circ}$ Encontro Nacional de Prática de ensino em Geografia. Trabalhos completos.

GRAZIOSI, M.E.S.; LIEBANO, R.E.; NAHAS, F.X. 2011. Pesquisa em Bases de dados. Módulo Científico, UNIFESP. 